\title{
Las fábricas del castillo de Almonaster la Real (HuElva)
}

Timoteo Rivera JimÉnEZ

EDUARDo RoMERo BOMBa

Recibido: 03/02/2016

Revisado: 25/05/2016

\section{RESUMEN}

Analizamos en el presente artículo las distintas fábricas de los paramentos del castillo de Almonaster la Real, realizando una propuesta de clasificación cronotipológica, y evolución constructiva del recinto, desde su construcción entre los s. X-XI hasta la actualidad.
Aceptado: 01/06/2016

Publicado: 30/06/2016

\section{ABSTRACT}

In this paper are studied the constructive reforms in the castel of Almonaster la Real (Huelva province, SW Spain). We propound a chronotypological classification and constructive evoluction of the enclosure, since its construction during X-XI centuries until today.
Palabras Clave

almonaster la real; castillo; arqueología de la arquitectura; medievo.

\section{KEYWORDS}

south west spain; castle; archaeology of architecture; medieval times.

trivera@andaluciaemprende.es

edu@telefonica.net 
El castillo de Almonaster la Real, descripCIÓN Y ESTADO ACTUAL.

El castillo de Almonaster la Real (Huelva) se localiza inmediato al casco urbano del propio municipio sobre un cerro que presenta una cota máxima de $610 \mathrm{~m}$ sobre el nivel del mar. Con pendientes no muy pronunciadas hacia las vertiente norte y noroeste, por donde se extiende el casco urbano de la localidad, es más abrupto hacia el sur y sureste. La ubicación topográfica del sitio le confiere una muy buena posición estratégica, con un importante dominio visual en todas direcciones, especialmente hacia el sur y el sureste, fácilmente defendible por la propia configuración topográfica natural.

El recinto es de planta irregular, con un perímetro total de 334 metros lineales y un área interior de $7640,50 \mathrm{~m}^{2}$. Atendiendo a la conformación actual del recinto se contabilizan ocho tramos rectos en su planta actual (figura 1). Conforme se accede desde el casco urbano de Almonaster la Real y siguiendo en el sentido de las agujas del reloj, se pueden distinguir los elementos que siguen.

En primer lugar, dos torres con planta de tendencia cuadrangular, que vamos a denominar en adelante como Torres 1 y 2 respectivamente, levantadas en su mayor parte con mampostería. En el coronamiento de la Torre 1 se aprecia la presencia de tapial, y también en la cara interna que da acceso al castillo es posible observar el arranque de uno

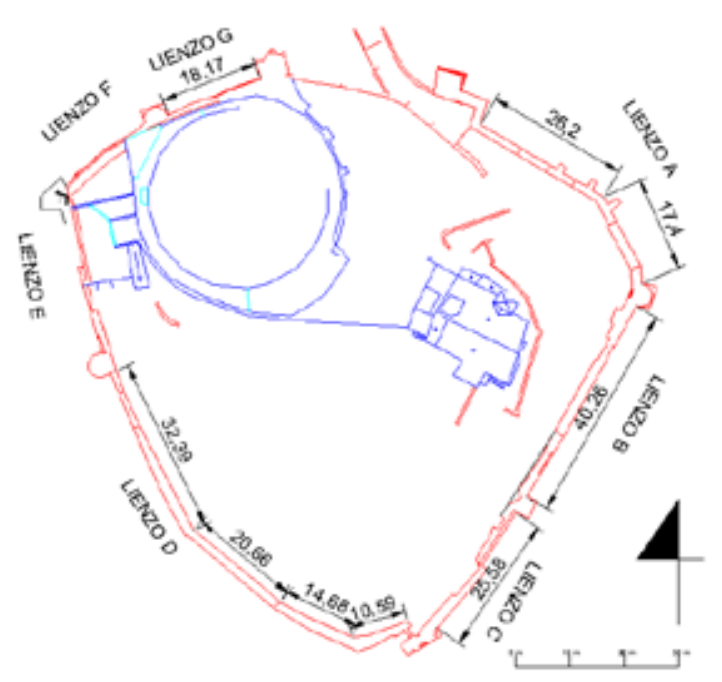

Figura 1: Plano actual del Castillo de Almonaster con la denominación propuesta para los lienzos y distancias de los mismos. de los arcos que debió formar parte de la entrada principal.

Le sigue un tramo de cortina (Lienzo A), que es posible dividir en dos partes por la presencia de un quiebro, la primera de $26,2 \mathrm{~m}$ y la segunda de 17,4 $\mathrm{m}$. El primer tramo de este lienzo es de mampostería, en apariencia totalmente contemporáneo, pues fue objeto de restauración en los años 70 . El segundo tramo es de fábrica de mampostería más antigua, y debe coresponder a alguna de sus reformas.

Después se encuentra una torre (Torre 3 ), circular en su coronamiento, pero con basamento de forma cuadrada. Está ejecutada también en mampostería, similar a la del segundo de los tramos del Lienzo A.

El siguiente lienzo (Lienzo B) tiene una longitud de 40,26 m de longitud, y en su aparejo es posible distinguir tapial y mampostería, correspondientes a distintas épocas. En este lienzo se conservan interiormente tanto el nivel del camino de ronda como restos del merlonado del recinto, ambos elementos de tapial.

A continuación encontramos la Torre 4 , de planta cuadrada y poco saliente, que además está ejecutada en mampostería y presenta sillares de granito reutilizados en su basamento. La fábrica de esta torre es la que se ha definido como califal (Jiménez Martín, 1975; Morales Martínez, 1976).

Le sigue un tramo de lienzo de $25,58 \mathrm{~m}$ (Lienzo C), cuya principal característica es que aproximadamente en la mitad de su desarrollo presenta un doble quiebro en ángulo recto. Este elemento o diseño del lienzo lo encontramos también en el castillo de Cumbres de San Bartolomé (Huelva), y como aquí parece ser tanto un recurso constructivo que permite adaptar el desarrollo del lienzo a un cambio brusco de la topografía del afloramiento, como un recurso defensivo (Rivera Jiménez y Romero Bomba, 2007, 9). Está construido en mampostería en su mitad inferior y tapial en la superior, y termina en su intersección con una torre de planta rectangular (Torre 5), de mampostería en su mitad inferior $y$ tapial en la superior. Conserva hacia el interior tanto el nivel del camino de ronda como parte del parapeto, y debió tener esquineras de ladrillos, hoy en su mayor parte desaparecidas. Esta torre a su vez forma parte de los elementos de la segunda entrada del recinto, una poterna muy alterada por las diversas restauraciones, que debió estar constituída originariamente por un arco que apoyaba en el tapial.

A partir de la poterna se desarrolla el Lienzo D, con hasta cuatro tramos rectos, con una longitud 
total de 78,32 m. y con ausencia de torres en su desarrollo. Es este último un lienzo muy complejo, con fábricas de tapial y fábricas de mampostería de diversas épocas, e incluye importantes restauraciones del siglo XX.

A continuación aparece una torre (Torre 6) de planta circular ejecutada en mampostería, a la que sigue un nuevo tramo de lienzo (Lienzo E), de $30,94 \mathrm{~m}$. Este tramo de lienzo está muy deteriorado, y corresponde en gran parte de su desarrollo a un muro de cierre del patio de cuadrillas de la Plaza de Toros.

Después se encuentra un tramo de cortina (Lienzo F) que forma prácticamente un ángulo recto con el anterior, y falta con seguridad una torre (Torre 7), como hemos puesto de manifiesto en trabajos anteriores (Rivera Jiménez y Romero Bomba, 2005). Este nuevo tramo de lienzo es casi por completo de tapial, tiene restos de encintado decorativo simulando sillares, y hacia el interior se ha conservado tanto el camino de ronda como las trazas del merlonado. Su longitud total es de 18,48 $\mathrm{m}$. El lienzo anterior finaliza en una torre de planta circular (Torre 8), prácticamente desaparecida, de la que sólo queda poco más de un metro de alzado y parte de su fábrica interior.

Finalmente se encuentra el Lienzo G, de 18,17 $\mathrm{m}$ de longitud, levantado con mampostería en su parte media y tapial en la superior, y la Torre 9, circular y de mampostería, que se encuentra basculada y semivolcada. Aunque en ella es posible ver lo que debió ser el arranque de un nuevo tramo de lienzo, éste no se ha conservado, y no es posible reconocer más elementos murarios originales entre este espacio y la Torre 1 situada en la entrada principal.

En el interior del castillo únicamente existen las dependencias correspondientes a la Iglesia de la Concepción, antigua mezquita, incluida la torre o alminar y el patio en el que se encuentra el aljibe, así como las dependencias de la Plaza de Toros, que ocupan el tercio noroeste del interior del recinto, asentando parte de sus graderíos sobre los propios elementos murarios del castillo.

ANTECEDENTES EN EL ESTUDIO DE LAS FÁBRICAS DEL Castillo de Almonaster la Real.

La producción bibliográfica sobre Almonaster la Real es bastante prolífica, en especial desde mediados de los 70 hasta la actualidad, aunque mayoritariamente centrada en la Iglesia de la Concepción. A pesar de ello han sido pocos los autores que han abordado el estudio del castillo propiamente dicho. A excepción hecha de varios artículos de los años 1911 y 1969 (Paz, 1911; Requena, 1969), no existen otras publicaciones que específicamente traten delo mismo. Las aportaciones que se han realizado forman parte de estudios que abordan otros elementos patrimoniales del municipio, fundamentalmente en el caso de F. Pérez Embid (1944) al estudiar la portada Manuelina de la Iglesia de San Miguel y muy especialmente de A. Jiménez Martín (2006) al estudiar la Iglesia de la Concepción, o en estudios de carácter general sobre la arquitectura medieval de la Sierra de Huelva, como es el caso de las publicaciones de A. Morales Martínez (1976) y de B. Pavón Maldonado (1996).

En su estudio sobre la Mezquita de Almonaster la Real Alfonso Jiménez realiza una clasificación de las fábricas de la cerca y una propuesta de evolución constructiva. Dejando a un lado reparaciones menores, reconoce cinco etapas, (Jiménez Martín, 1975). Por orden cronológico de la más antigua a la más reciente, en primer lugar describe la que denomina fábrica A, mampostería de piedra del lugar en hiladas alternantes con lajas, que conserva la horizontalidad de los tendeles y está tomada con mortero pobre de cal, actualmente muy descarnada. Señala que suele llevar sillares graníticos para la protección de las esquinas y aporta una fotografía (lamina 13 a) que corresponde a la que nosotros denominamos Torre 4 , situada entre los lienzos B y C. La segunda de las fábricas descritas es la fábrica B, tapial con tierra roja, con abundantes fragmentos de pizarra, piedrecilla y poca cal. Señala también al respecto que no observa la distinción de cajones de encofrado que suelen presentar los tapiales almohades y almorávides, ni estratificación por tongadas, y presenta en cambio unas grandes juntas inclinadas, para las que por entonces no se conocían paralelos. Al igual que para la fábrica $\mathrm{A}$, muestra una fotografía (lamina 13 b) de la junta inclinada de uno de los cajones de tapial, que se corresponde con la cara interior del lienzo $\mathrm{D}$, en una zona inmediata a la poterna. La fábrica $\mathrm{C}$ se describe como mampostería incierta tomada con mortero de cal que rebosa las llagas, proporcionando un enlucido casi total de la fábrica. La fábrica $\mathrm{D}$ son recalces en la fábrica de tapial con mampostería muy desigual, y la fábrica E reparaciones modernas con fábrica mixta de ladrillos y piedra totalmente enlucidas.

El autor no publica alzado de las cercas del recinto, pero aporta una descripción en la que incluye 
las fábricas presentes. Parte de la entrada principal, que describe como torre rectangular en cuyo costado norte se abría una puerta en recodo, obligando al posible asaltante a presentar el costado derecho desguarnecido, que aparece construida con las fábricas $\mathrm{B}, \mathrm{C}$ y $\mathrm{D}$, y señala que sólo excavaciones futuras podrán determinar si la entrada en recodo formó la entrada desde el principio. Del lienzo que continúa en sentido horario a la torre de la entrada principal (Lienzo A) y hasta el primer cubo circular (Torre 3) apunta únicamente su longitud de $51 \mathrm{~m}$. Lo describe como muy destruido por un corrimiento de tierra que lo ha desplazado, y que parece no tuvo torres intermedias. Del cubo circular (Torre 3) anota que presenta la fábrica $\mathrm{C}$, aunque en el arranque del cubo quedan restos de la fábrica $\mathrm{A}$, que muestran que originalmente fue de planta rectangular y escasa proyección al exterior. Sigue un tramo recto de lienzo (Lienzo B) de $39 \mathrm{~m}$ de longitud, que tiene gran parte de fábrica $\mathrm{B}$ con algunas reparaciones, y conserva parte del camino de ronda, con su parapeto, todo en tapial. Este lienzo termina en una torre rectangular (Torre 4), realizada en fábrica A. Continua un lienzo de $42 \mathrm{~m}$ dividido en dos partes por un quiebro en ángulo recto, que continúa hasta la puerta accesoria, en el que no clasifica las fábricas. La poterna la describe como formada por un desdoblamiento de la muralla, de tal manera que en el estrecho pasillo que los dos lienzos paralelos dejan, existió un arco de tapial y otros elementos defensivos tan retocados con fábrica del tipo $\mathrm{E}$ y soterrados que no resultan inteligibles. Afirma que esta puerta obligaba al enemigo a presentar el costado izquierdo hacia la muralla y que los defensores carecían de torres de flanqueo. A partir de aquí la descripción de los paramentos y sus fábricas resulta mucho más escueta. Únicamente se señala la existencia de $25 \mathrm{~m}$ de fábrica sin especificar de qué tipo, que desaparece en los $51 \mathrm{~m}$ siguientes para reaparecer en forma de cubo semicilíndrico realizado en fábrica C, y seguidamente vuelve a desaparecer soterrada sobre escombros en una longitud de $27 \mathrm{~m}$. Sobre el resto del recinto señala únicamente los 57 $\mathrm{m}$ de lienzos que sirven de apoyo al graderío de la plaza de toros, que presenta dos cubos, uno del que apenas se conserva un metro escaso de altura y otro que por un corrimiento se ha desgajado del muro.

Finalmente, a partir de los datos expuestos más los manejados sobre la mezquita y la documentación histórica, A. Jiménez propone una evolución constructiva, muy sucinta, en la que parte de una fortaleza o población fortificada de época califal, a la que pertenecería la mezquita y las zonas de cerca de fábrica A. Con posterioridad a la fitna, se realizaría el refuerzo general de los lienzos con la fábrica de tapial (fábrica B), y la reorganización de ambas puertas. La datación del tapial en esta época la remite en nota a pie a un comentario de D. Félix Hernández, para quien el tapial de la cerca de Almonaster la Real podía clasificarse entre los califales por su espesor, ya que en época posterior suele ser notablemente mayor. Tras la reconquista y hasta los Reyes Católicos sitúa las reparaciones en los paramentos con la fábrica $\mathrm{C}$ y la modificación de las torres, para reducirlas a cubo. A partir de 1479 decaería el interés por la fortaleza, tanto por estar en segunda línea como por pertenecer al Arzobispado de Sevilla, y las últimas obras corresponderían a la etapa restauradora de la segunda mitad del siglo XX.

En su obra Arquitectura Medieval en la Sierra de Aracena Alfredo Morales Martínez también aporta información referente a las fábricas del castillo de Almonaster la Real, su descripción y clasificación (A. Morales Martínez (1976). En el análisis que realiza de los tipos de fábrica presentes en la arquitectura medieval de la Sierra de Huelva, distingue varios, sillería, mampostería, fábrica de ladrillos, y tapial. En la mampostería establece a su vez una diferenciación en tipológica en tres tipos, mampostería concertada, aparejo toledano y aparejo incierto. La mampostería concertada la define como formada por hiladas de altura regular, de 20 a $40 \mathrm{~cm}$, con abundantes ripios de pizarra para igualar alturas, con poco mortero, de forma que la construcción es casi en seco, y cita como ejemplo más claro de este tipo de fábrica la fase primitiva del castillo de Almonaster la Real, fábrica que data, siguiendo a Florentino Pérez Embid, en fase califal. En cuanto al tapial distingue dos tipos, el que denomina forma habitual andaluza, tierra con cal apisonada entre tableros y por tongadas, y un segundo tipo, del que señala es bastante raro en las construcciones peninsulares, y que es característico de la cerca de Almonaster la Real, donde se dispusieron grandes encofrados sin solución de continuidad, con agujas muy pequeñas que han dejado unos mechinales muy estrechos y próximos y extrañas juntas inclinadas. En cualquier caso es irregular y de intenso color rojo sin que se haya visto en ningún sitio paja o ramas en la masa, como es habitual en Castilla, y faltan también las estructuras leñosas que aparecen en fortificaciones de tapial del Valle del Guadal- 
quivir.En el mismo apartado de descripción de las fábricas de mampostería referido con anterioridad, afirma que la mampostería más compleja de toda la Sierra de Huelva es la del castillo de Almonaster la Real, realizada en piedra pizarrosa de fuerte color negruzco, brillante a veces, en el que diferencia las siguientes fases. La Fase 1, mampostería concertada con esquinales y refuerzos de enormes sillares graníticos romanos reaprovechados, que fecha como posiblemente de época califal, de la que aporta como ejemplo de esta fábrica una fotografía de los paramentos del castillo de Almonaster la Real, que se corresponde con la Torre 4 y el Lienzo C. La Fase 2 correspondería con las fábricas de tapial, para la que no aporta cronología alguna. La Fase 3 es mampostería incierta con grandes revocos de cal, la denomina de refuerzos cristianos, y la asemeja con las fábricas del castillo de Cumbres Mayores. Aunque no aporta fechas en la descripción, por la semejanza que realiza con las fábricas del castillo de Cumbres Mayores, es deducible que la cronología que baraja para esta fase se situaría entre fines del siglo XIII y comienzos del XIV. La cuarta y última fase de A. Morales correspondería a las restauraciones del siglo XX, para la que señalas que se mezclan mampuestos, ladrillos y tejas, con fechas entre 1946 y 1950.

Otro de los autores que se ha ocupado del Castillo de Almonaster la Real desde el punto de vista de su caracterización formal, evolución constructiva y/o caracterización de sus fábricas, ha sido Basilio Pavón Maldonado (1996), aunque de forma más parcial y menos sistemática que A. Jiménez o A. Morales. Señala que las tapias de Almonaster la Real tienen 0,75 metros de altura según los mechinales de las agujas de madera y las considera del siglo X. Describe los muros como de entre 1,80 y $2 \mathrm{~m}$ de espesor, y considera que la mampostería exterior es un mero enchapado del muro de tapial. Al describir las torres refiere que son rectangulares, de escaso saliente, y algún cubo o torre semicircular, posiblemente añadida en una de las reformas. Explica que la Torre Mayor se sitúa donde estaría la entrada principal, con dos zarpas o escalones muy propios de los muros omeyas, y por el tapial que aflora deduce que las partes superiores de toda la muralla serían de tapial, como en otras fortalezas musulmanas castellanas y andaluzas del siglo X y XI. Para Pavón Maldonado las puertas de esta fortaleza son un problema aún por dilucidar. La poterna la define como desdoblamiento de la muralla, diseño que cree se repetiría en la principal, que no es para él en recodo, aunque posteriormente señala que no puede descartarse del todo la existencia en Almonaster la Realde puerta en recodo. Cita la puerta cristiana de Duruelo en Sepúlveda como paralelo que explicaría a la perfección la entrada principal de Almonaster la Real, una puerta formada por un arco de medio punto con cubos rectangulares a los lados.

DESCRIPCIÓN Y CARACTERIZACIÓN DE LAS FÁBRICAS del Castillo de Almonaster la Real.

Para el estudio y caracterización de las fábricas del castillo de Almonaster hemos procedido a realizar el análisis paramental de sus elementos murarios, circunscrito a los paramentos defensivos. Por tanto, excluimos las construcciones internas, tanto la edificación de la Iglesia de la Concepción como las edificaciones de la Plaza de Toros. En el desarrollo del trabajo realizamos en primer lugar el levantamiento de los alzados exteriores del recinto apoyándonos en la cartografía existente, fundamentalmente el plano elaborado por el arquitecto Eduardo del Valle en el año 2004. A partir del mismo, elaboramos unos alzados previos, que solo contuviesen el contorno de los paramentos murarios. Apoyándonos en fotografías, realizamos una lectura paramental previa del elemento emergente en cuestión, y procedimos a identificar las distintas unidades constructivas diferenciables, así como las relaciones estratigráficas existentes entre las mismas. Posteriormente, mediante estación total laser tomamos puntos del contorno de cada una de las unidades diferenciadas en el análisis arquitectónico, y complementamos el alzado de partida mediante nuevas mediciones. Finalmente, vectorizamos el contorno de las distintas unidades diferenciadas en el análisis murario mediante fotografía y lo incorporamos al alzado correspondiente, apoyándonos en los puntos de control y contorno previamente introducidos con ayuda de la herramienta Adersheet (deformación elástica) que dispone el programa AutoCAD Map.

La clasificación cronotipológica que realizamos de las fábricas del Castillo de Almonaster la Real no es únicamente el resultado del estudio paramental, sino también de la valoración conjunta de la información deparada por sendas campañas de intervención arqueológica realizadas por nosotros mismos, así como un exhaustivo estudio histórico realizado con carácter previo a la campaña de intervención arqueológica del año 2007. De igual 
manera, en la propuesta que presentamos, tenemos también en consideración el conocimiento adquirido en los estudios paramentales que hemos realizado en otros recintos fortificados de la Sierra de Huelva, especialmente en el castillo de Aroche, el castillo de Cala y el castillo de Cumbres de San Bartolomé.

Por la disponibilidad de espacio resulta imposible abordar una descripción exhaustiva de todas y cada una de las unidades estratigráficas verticales diferenciadas, pero las diferenciamos tanto a nivel gráfico en los alzados correspondientes como en la Matrix Harris que los acompaña (figura 2). Hemos preferido presentar los resultados del trabajo agrupando estas unidades en grandes tipos crono-tipológicos, y se han diferenciado tres grandes grupos: fábricas islámicas, fábricas cristianas y fábricas contemporáneas. Distinguimos a su vez en la fábricas islámicas las que creemos fueron ejecutadas entre los siglos X-XI y las realizadas a lo largo del siglo XII y primera mitad del XIII. Las fábricas denominadas cristianas también las hemos subdividido entre fábricas de los siglos XIII-XIV y fábricas del siglo XV y posteriores hasta época contemporánea. Para cada uno de estos grupos y subgrupos, vamos a describir lo que consideramos tipos básicos, comentando brevemente las variaciones observadas, y resaltando sus relaciones estratigráficas más significativas y los datos que de forma más clara nos han ayudado para la adscripción a uno u otro grupo.

\section{FÁBRICAS IsLÁMICAS.}

Mampostería andalusí de los siglos X-XI d.C. Como indica el propio título que le hemos asignado, se trata de una fábrica de mampostería cuya principal característica es la disposición horizontal de los mampuestos, separados por hiladas horizontales de lajas y tendeles de unos 25 centímetros de grosor. Los mampuestos son de mediano tamaño, con formas aproximadamente rectangulares, de entre 25 y $35 \mathrm{~cm}$ de anchura y $10-20 \mathrm{~cm}$ de grosor. Predominan las metagrauvacas, de colores grisáceos, en tonos oscuros, y en menor medida cuarcitas, de tonalidades más claras. Las lajas dispuestas entre los mampuestos suelen ser fragmentos de esquistos del propio cerro donde asienta el recinto murario. Nos inclinamos a considerar que originariamente la fábrica se labró con un mortero pobre en cal, colocando los mampuestos prácticamente a hueso, de ahí probablemente la necesidad de enripiar con fragmentos de lajas. De este tipo básico, que aparece signado en la matrix Harris como 4-2 precedido de las letras identificativas del paramento, quedan evidencias tanto en la parte no restaurada de la Torre 4 como en la zona media del Lienzo D.

Es sin embargo una variante de este tipo básico, signado en la matrix Harris como 4-3, es el mejor representado. Mantiene la disposición horizontal de los mampuestos y la conformación de tendeles, pero aparece enripiado de forma dispersa con fragmentos de teja y ladrillos, y las juntas tomadas con mortero de cal, sin rebosar las llagas. Así aparece en la mitad inferior del Lienzo B, en contacto con la Torre 4, en los lienzo C y D, y con menor presencia de ladrillo e incluso sin ellos Torres 2 y 5 , con las llagas tomadas con mortero.

Una tercera variante de este mismo tipo, 4-1 en la matrix Harris, la fundamentamos más en las relaciones estratigráficas que en las propias características formales, por cuanto ocupan superficies en las que resulta difícil de percibir. Está presente únicamente en las evidencias de los basamentos cuadrados preexistentes de las Torres 3 y 8 . En el caso de la Torre 3 contacta con una fábrica que posteriormente describiremos, que creemos posterior al siglo XV. Muy evidentes son las relaciones estratigráficas respecto al tapial en los restos conservados de la Torre 8, donde se manifiesta su anterioridad constructiva. También en la Torre 6 parece que pudo existir con carácter previo un basamento cuadrado, actualmente sepultado por los escombros y residuos que se vienen arrojando desde ella.

Este primer tipo incluye sin lugar a dudas la fábrica Tipo A de A. Jiménez, coincidente con el que hemos considerado tipo básico más la variante diferenciada en los restos de basamento cuadrado de las torres, y la fábrica concertada de Alfredo Morales, que incluiría la primera de las variantes descrita. Para B. Pavón se trataría sin embargo de un contrachapado de la fábrica de tapial (Pavón Maldonado, 1996, 252), cuestión que debemos descartar, especialmente si analizamos las relaciones estratigráficas entre el tapial y la fábrica en cuestión. Además, en el Lienzo $C$ hay una pérdida de mampostería que permite apreciar la trabazón entre la mampostería con la matriz interior del muro, sin que exista refracción alguna.

Establecemos la datación de esta fábrica y sus variantes entre los siglos X-XI. En primer lugar la establecemos en primer lugar atendiendo a las relaciones estratigráficas respecto al tapial, que claramente ponen de manifiesto su anterioridad 

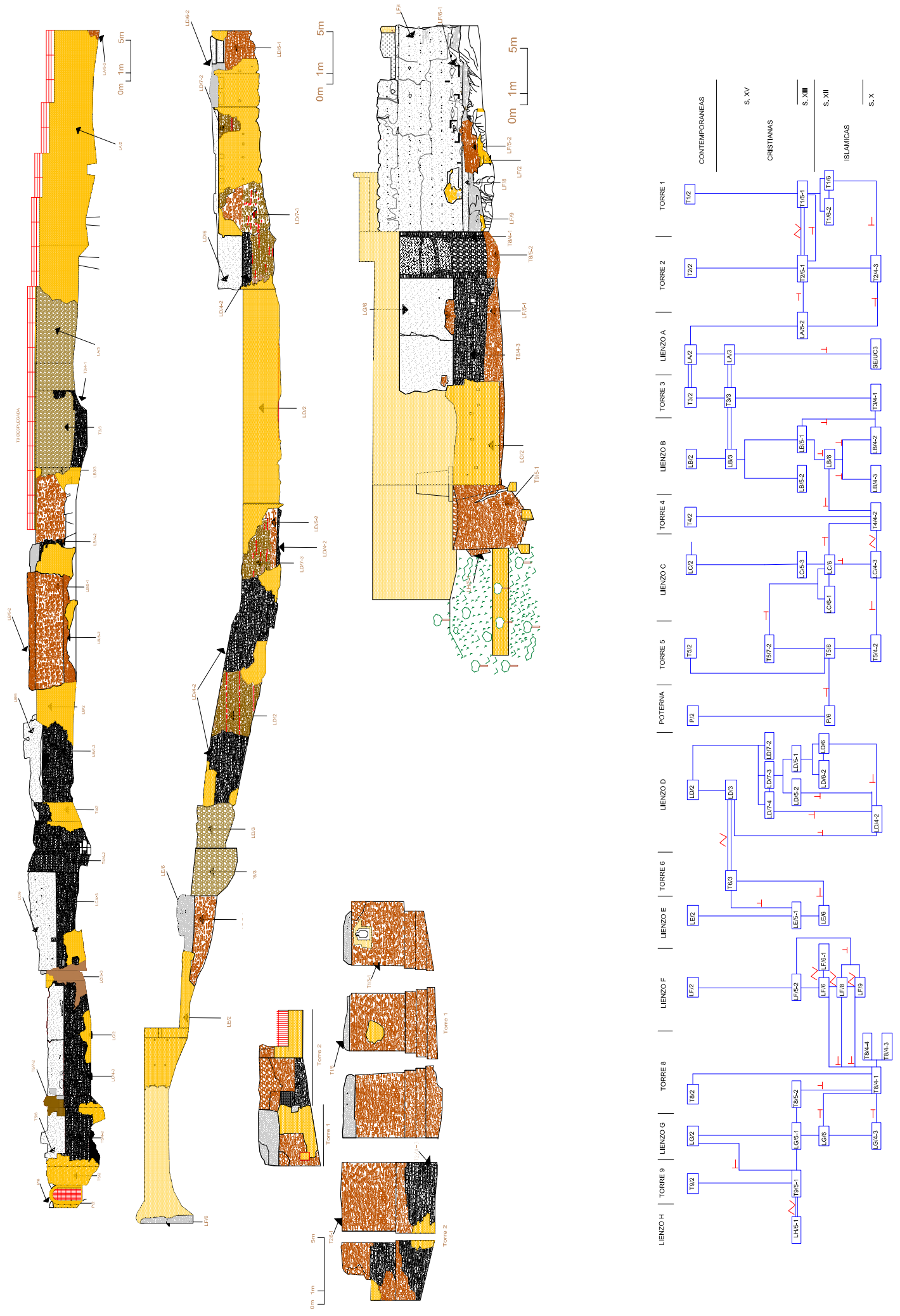

Figura 2: Alzados exteriores del castillo de Almonaster la Real (Huelva), con identificación de sus fábricas y matrix Harris. 

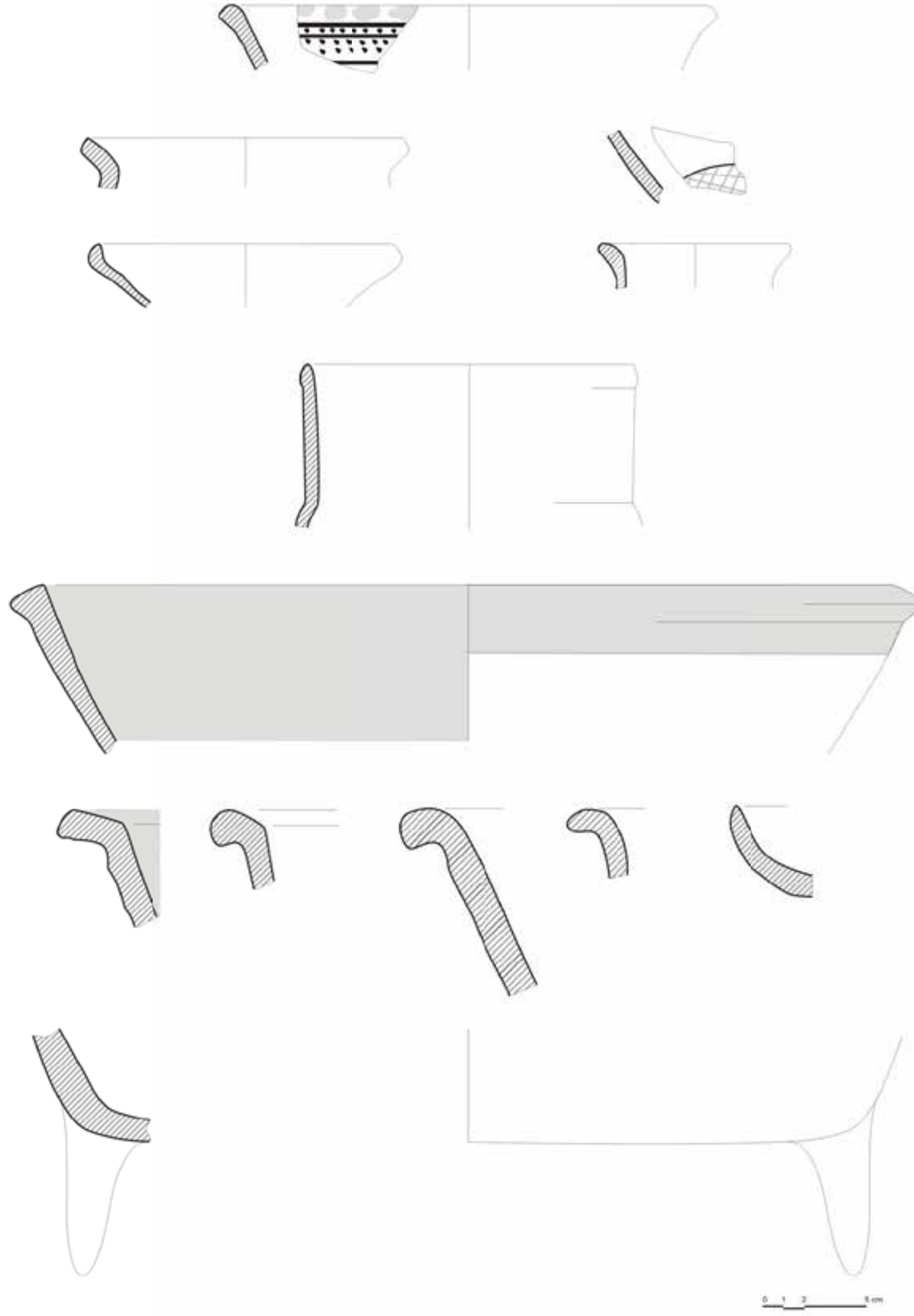

Figura 3: Materiales califales/taifas exhumados en el sondeo 3, campaña del año 2007. 


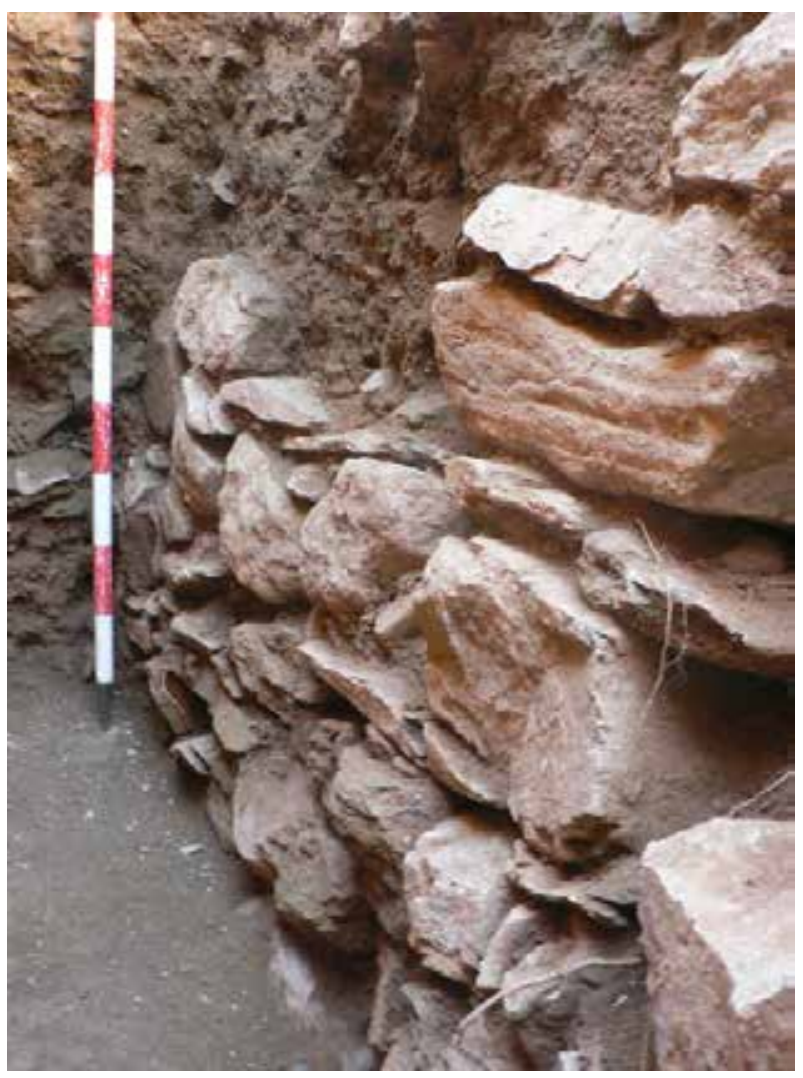

Figura 4: Detalle de muro con mampuestos colocados a hueso, aparecido en el sonde 3 de la campaña del 2007, en niveles califales/taifa.

constructiva. Y en segundo lugar, en la Torre 8 y sus relaciones con los tapiales de los lienzos $\mathrm{F}$ y $\mathrm{G}$, en la que el adosamiento es muy evidente. En la confluencia del Lienzo C y la Torre 4 podemos comprobar la trabazón existente entre la fábrica de mampostería de la torre y el lienzo, demostrando por tanto que son coetáneas.

Por otro lado, contamos también con los resultados de la intervención arqueológica del año 2007 , especialmente el Sondeo 3, que nos deparó en sus niveles inferiores una interesante muestra de materiales adscribibles a este periodo (figura 3 ), pero no nos permiten discriminar si corresponde al periodo califal o taifa. Más aún teniendo en cuenta que en las recientes excavaciones en el castillo de Aracena contextos cerámicos similares, han sido fechados mediante hallazgos numismáticos a mediados del siglo XI (Canto García, Romero Bomba, Rivera Jiménez y Romero de la Osa Fernández; 2015). En este mismo sondeo excavamos parcialmente una estructura muraria, perpendicular al Lienzo A, cuya fábrica responde al mismo típico básico descrito, en

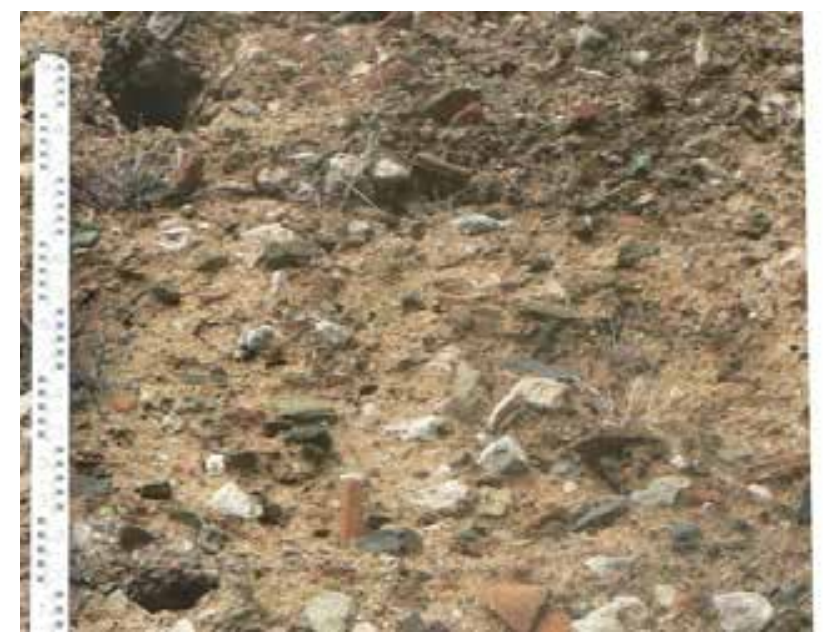

Figura 5: Detalle de la fábrica de tapial en el Lienzo C (LC-6).

la que los mampuestos aparecen colocados a hueso (figura 4).

De la distribución de esta fábrica se extrae una importante conclusión, que corresponden a la fase fundacional del recinto, y que éste no ha sufrido variaciones en lo relativo al perímetro amurallado.

El segundo de los tipos de fábricas islámicas que vamos a describir la denominamos mampostería islámica del siglo XII y la primera mitad del siglo XIII d.C., signado en la matrix Harris como LF/9. Se trata también de una fábrica de mampostería que únicamente hemos reconocido en el Lienzo $\mathrm{F}$, en la zona de contacto con la Torre 8. Está formada por mampuestos de reducidas dimensiones, la mayor parte de ellos fragmentos de pizarra/esquistos que muestran en su cara frontal los planos de exfoliación. Están tomados con mortero rico en cal y sin formar alineaciones. Se trata sin lugar a dudas de un recurso constructivo empleado para nivelar el asiento del tapial entre los afloramientos. La última hilada de mampuestos contiene pequeños mechinales que sirvieron ya para edificar el tapial. La cara externa de la fábrica no forma plano con el tapial, sino que se distribuye en talud desde el afloramiento. Originariamente debió extenderse a lo largo de todo el desarrollo longitudinal del lienzo, adaptándose a la topografía del afloramiento, pero actualmente hacia la zona media aparece primero una pérdida que deja ver la matriz, un hormigón muy rico en cal de tono amarillento, con mampuestos en su interior similares a los que conforma la cara externa del muro, y a continuación una fábrica de mampostería sin enfoscar que posteriormente describire- 


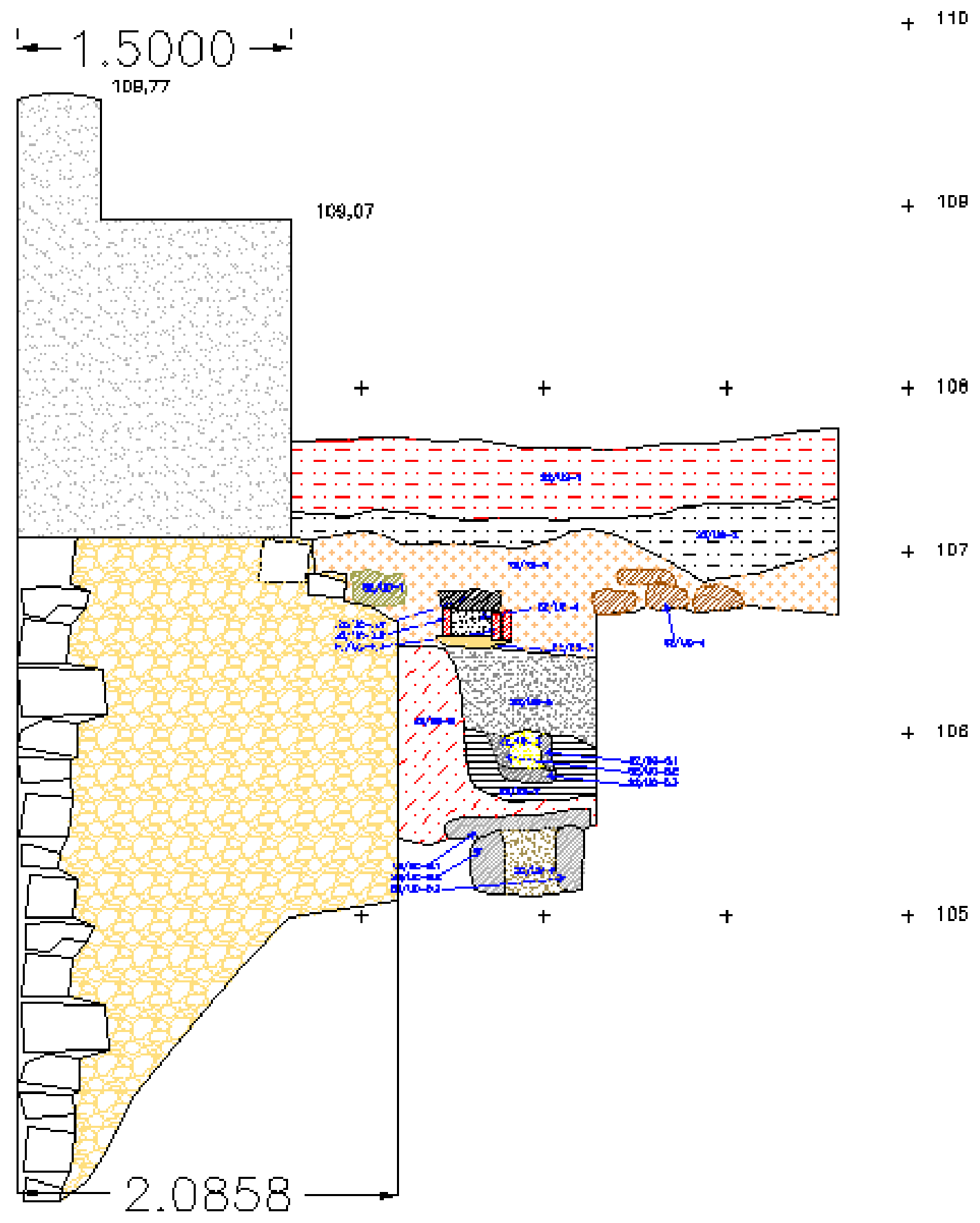

Figura 6: Estratigrafía del sondeo 2, campaña 2007, con identificación de tres niveles de atarjeas supuerpuestos y grosor diferenciar del lienzo. 
mos. Estratigráficamente se adosa con la fábrica de mampostería de los siglos X-XI d.C. de la Torre 8, $\mathrm{y}$ como se ha indicado traba con el tapial del Lienzo $\mathrm{F}$, siendo por tanto su cronología la misma que la del propio tapial.

El tapial del castillo de Almonaster la Real corresponde al tercero de los tipos analizados y está realizado con un hormigón de cal, tierra, cantos de pequeño tamaño tipo grava de textura esquistosa (materiales del propio cerro), fragmentos de cerámica de diversos tipos, a veces algún hueso y restos de escorias de hierro, signado en la matrix Harris como tipo 6 y sus variantes. Presenta una tonalidad de color castaño claro, que se torna unas veces rojiza y en otras grisácea hacia el interior cuando presenta pérdidas. Las mediciones que hemos realizado de la altura de los cajones nos arroja una media de $0,80 \mathrm{~m}$ (figura 5), con picos entre 0,75 y $0,85 \mathrm{~m}$., salvo en el caso de haberse conservado completo el último cajón que formaría parte del almenado, como ocurre en el Lienzo F, con alturas superiores a los $0,90 \mathrm{~m}$. La anchura, bastante más difícil de contrastar, nos arroja valores de entorno a los 2,56 en el Lienzo F. En este mismo lienzo hemos podido documentar la presencia de encintado sobre la superficie externa, 6-1 en la matrix Harris. Se trata de franjas horizontales y verticales formando rectángulos de enfoscado de color blanco, que sobresalen unos milímetros de la superficie externa del tapial, con una anchura de 0,7 mm. Suponemos que originariamente debió estar presente en todos los paños, y quedan huellas de los mismos en los Lienzos B y C. En ocasiones el contacto entre dos cajones consecutivos no es vertical, sino inclinado, formando un ángulo aproximado de $45^{\circ}$, como sucede en el Lienzo C y en la cara interna del Lienzo $\mathrm{D}$, en las proximidades de la poterna, particularidad que pensamos que es más bien de tipo constructivo, motivada por el propio desarrollo de la obra, sin que tenga significación cronológica ni tipológica.

Otro aspecto a subrayar es la constatación de anchuras diferenciales en los muros de tapial. Así en el Lienzo B, coincidiendo hacia el interior con el Sondeo 2 de la campaña del año 2007, medimos una anchura de 1,50 m, 1,60 m en el tapial del Lienzo D, coincidiendo hacia el interior con el Sondeo 4 , y $1,75 \mathrm{~m}$ de anchura en el Lienzo F. Tanto en el sondeo 2 como en el 4 comprobamos también la disminución del grosor del lienzo coincidiendo con el contacto de la fábrica de tapial con las fábricas preexistentes, muy evidente en el caso del sondeo 2

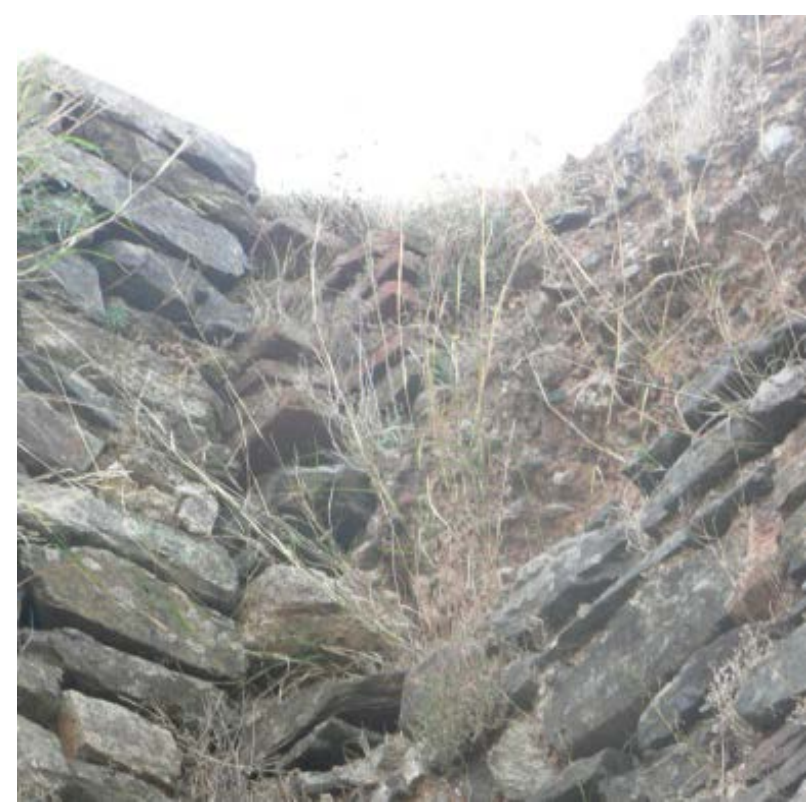

Figura 7: Detalle del adosamiento de las fábricas de la Torre 2 sobre Torre 1, y la presencia en esta última de restos de fábrica de ladrillos en lo que pudo ser una esquinera que enmarcaba el tapial.

(figura 6) en el que se pasa de una anchura de 2,08 metros a los ya señalados 1,50 m. La disminución del grosor se verifica siempre hacia el interior del recinto, siendo las fábricas coplanarias hacia el exterior.

Otra particularidad presente en los tapiales del castillo de Almonaster la Real es la presencia de retazos de otras fábricas insertos en la propia matriz del tapial, pero tiene tan escasa significación espacial que no merece la diferenciación como fábrica independiente. Podemos diferenciar tres variantes, fábrica de mampostería, mampostería y ladrillos, y ladrillos de forma exclusiva.

La presencia de mampostería aparece en los lienzos C y F. En el Lienzo C, en el primero de los tramos de tapial, a partir de su zona media y en dirección al quiebro, aparecen dos elementos en vertical, uno muy visible, y el otro en la intersección con el quiebro, recubierto por un enfoscado de color blanquecino. En los alzados y matrix se ha considerado como fábrica de mampostería califal-taifa. $\mathrm{Su}$ altura coincide exactamente con la altura del cajón de tapial, unos $0,80 \mathrm{~m}$, y tiene una anchura de aproximadamente $0,40 \mathrm{~m}$. Su presencia condiciona la menor anchura de los cajones de tapial situados entre ambos respecto a los cajones superiores.

Cuando menos, son por tanto constructivamente coetáneos al tapial, dado que no se trata de una 
refacción, aunque lo más lógico es que sean anteriores. En este caso podría tratarse de restos de fábrica de mampostería de los siglos X-XI d. C, lo que demostraría que originariamente se extendía hasta una cota superior a la actual, y que cuando se le adosó el tapial se produjo antes un rebaje del nivel de la fábrica. Otra opción es que se trate de restos del primitivo almenado del recinto de época califaltaifa, amortizado con la construcción del tapial.

En el Lienzo $\mathrm{F}$ encontramos también dos zonas con presencia de mampostería en la cara externa del tapial, ambas en la esquina derecha, en la zona que originariamente debió estar ocupada por la desaparecida Torre 7 , pero no se ha diferenciado a nivel gráfico ni en alzados y ni en la matrix Harris. Una en la parte inferior, en contacto con el afloramiento, y otra en la parte superior del lienzo, por debajo del nivel del adarve. En este caso entendemos que se trata de elementos constructivos cuya función sería la de servir de trabazón entre la fábrica del lienzo y la torre. Con la misma funcionalidad de trabazón, en este caso entre la esquinera de la Torre 5 y el Lienzo $\mathrm{C}$, detectamos una pequeña área con mampostería y verdugadas de ladrillos, que interpretamos como posterior al tapial y coetánea a la reconstrucción de la esquinera de la torre en el siglo XV.

La presencia de ladrillos en la fábrica de tapial del castillo de Almonaster la Real, 6-2 en la matrix Harris, es muy reducida. Algunos se encuentran insertos en el propio tapial, formando los laterales de los desagües, o la parte superior de los huecos de las agujas. En la Torre 5 existen evidencias que sugieren que originariamente sus esquineras fueron

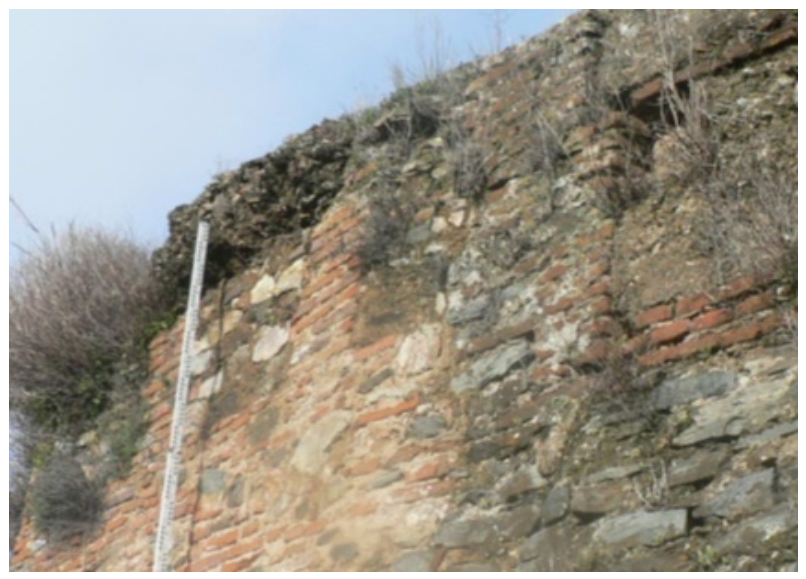

Figura 8: Detalle de restos de tapial que sobresalen sobre la rasante en el lienzo D, proximidades de la poterna, donde suponemos pudo existir una torre hoy desaparecida.

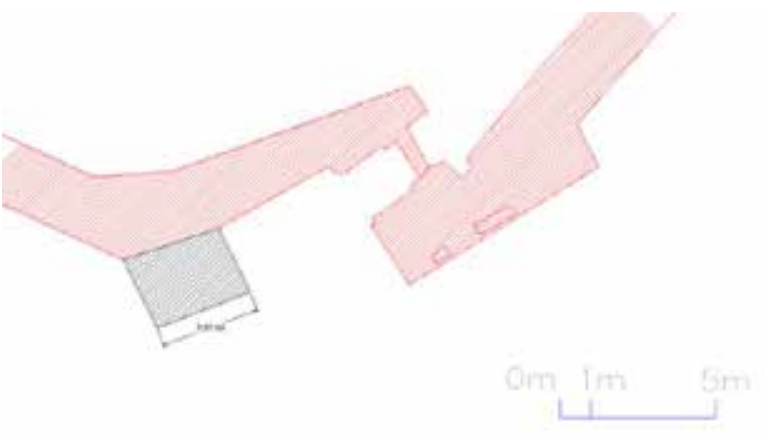

Figura 9: Croquis sobre la planimetría actual de la posible ubicación de una torre, actualmente desaparecida, que serviría para conformar una entrada en eje acodado en la poterna.

íntegramente de ladrillos. También la Torre 1 muestra restos de esquinera de ladrillos en el contacto con la Torre 2 (figura 7). En el Lienzo D, en las proximidades de la poterna, aparecen dos cajones de tapial superpuestos, de los cuales el inferior aparece enmarcado inferiormente por tres hiladas de ladrillos y una en la parte superior. Lateralmente, en su lado izquierdo, el único que se conserva no restaurado, ambos están enmarcados por un área de fábrica de ladrillos, a modo de esquinera de torre. Esta zona resulta compleja de interpretar, debió ser restaurada por R. Manzano en los años 70. La presencia de los ladrillos, su propia disposición y el hecho de que la fábrica de tapial no coincide en plano con la fábrica inferior restaurada por R. Manzano, ni con el tapial situado a su derecha, no restaurado (figura 8), nos hacen sospechar la posible existencia de una Torre, desaparecida actualmente por completo. La propia configuración en planta del lienzo en este punto resulta idónea, primero por coincidir con dos quiebros en un corto espacio, y en segundo lugar por la presencia de la poterna. Si hubo una torre, entonces el ingreso desde la poterna no fue directo, sino en eje acodado (figura 9), muy similar al diseño que creemos existió en la entrada principal. Por el espacio disponible se trataría de una torre escasamente saliente, similar en dimensiones a la actual Torre 4. Algunos datos históricos, que no vamos a analizar en este trabajo, podrían también avalar esta hipótesis. Además en su restauración en esta zona R. Manzano dibuja un extraño almenado con fábricas de ladrillo, en el mismo espacio que en teoría debía ocupar la torre.

Respecto al que podemos considerar el tipo general de las fábricas de tapial en el castillo de Almo- 
naster la Real, cabría precisar una variante, únicamente presente en el Lienzo F. El primer cajón de tapial de este lienzo, superpuesto a la mampostería islámica de los siglos XII-1 $1 / 2$ del XIII d. C., presenta una matriz pobre en cal, solo con numerosos fragmentos de esquistos de tamaño grava, carente de fragmentos de material constructivo o cerámico. Tiene este cajón una anchura máxima de $0,50 \mathrm{~m}, \mathrm{y}$ se extiende en horizontal desde la intersección con la Torre 8 hasta aproximadamente la zona media del lienzo, tapado en parte por una reforma posterior y erosionado en la mitad derecha del lienzo. No es coplanario respecto al resto de fábrica de tapial, sobresale unos $15 \mathrm{~cm}$, configurando una zarpa o pie de amigo. Además de trabarse con la mampostería situada por debajo, lo hace con el tapial de por encima. Como ya explicamos respecto a la mampostería, se trata en este caso también de un recurso constructivo utilizado para la nivelación de la base del lienzo, y por tanto coetáneo tanto a la mampostería como al tapial.

Para la datación de la fábrica de tapial debemos fundamentarnos en la muestra de materiales recogidos en el seguimiento de obras que realizamos en el Lienzo F, haciendo extensible dicha cronología al resto de paños de tapial. Estos materiales apuntan como fecha más tardía hacia finales del siglo XII y principios del XIII d. C. (Rivera Jiménez y Romero Bomba, 2005), fecha que concuerda con la obtenida para los tapiales del castillo de Aroche

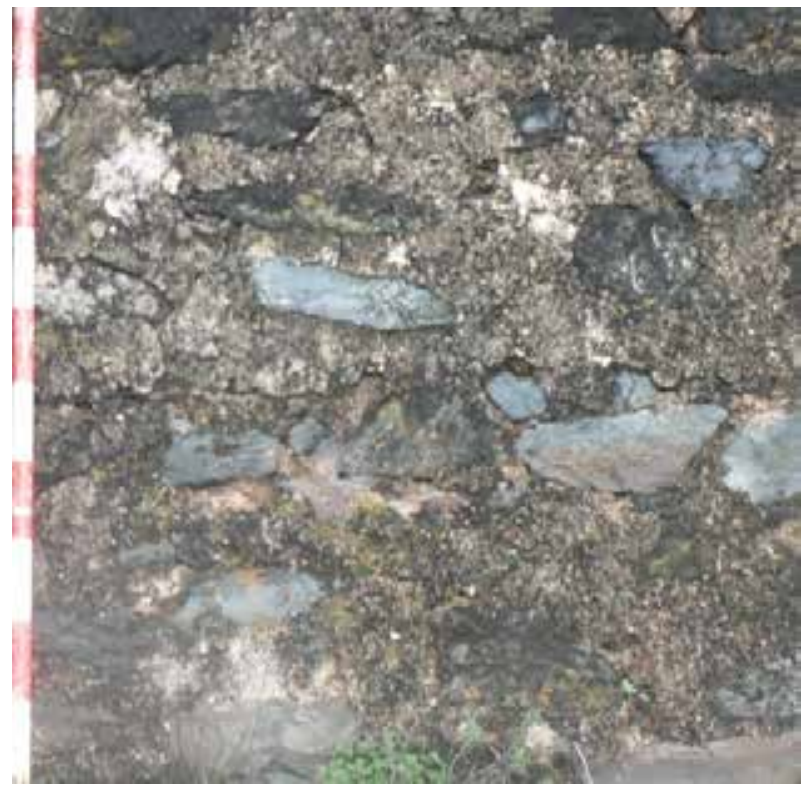

Figura 10: Detalle de la fábrica de mampostería con enfoscado a raspaterrón. Suptipo 5-1.

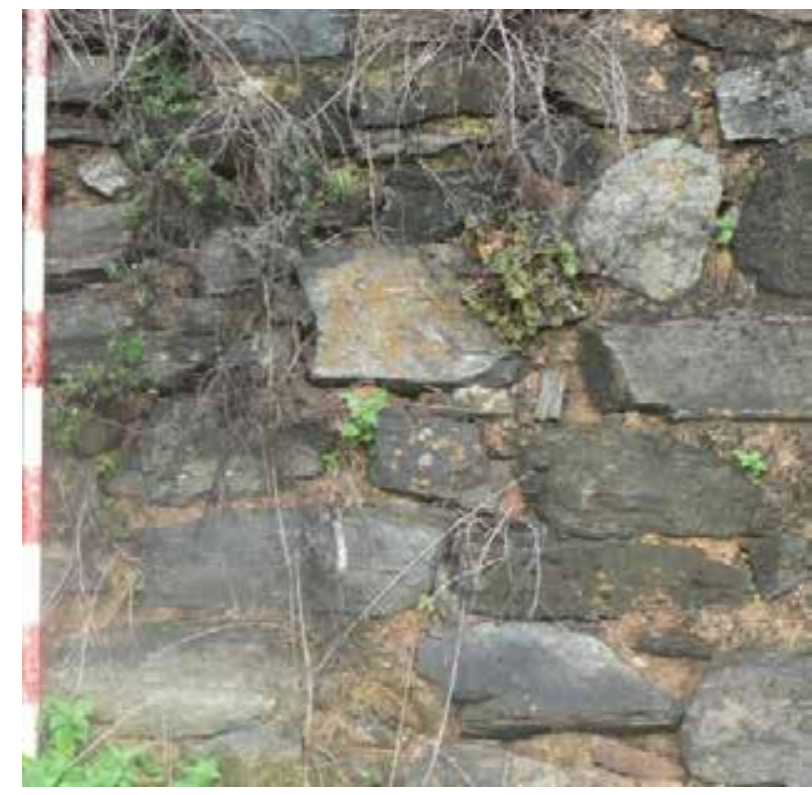

Figura 11: Detalle de la fábrica de mampostería sin enfoscar. Subtiipo 5-2.

mediante datación radiocarbónica de un fragmento de madera de una de sus agujas (Rivera Jiménez y Romero Bomba 2005, 12)

\section{FÁBRICAS CRISTIANAS.}

En la descripción y caracterización de las fábricas que consideramos de época cristina vamos a diferenciar dos grupos cronológicos. Por un lado aquellas fábricas cuya datación podemos fechar entre la $2^{\mathrm{a}} 1 / 2$ del siglo XIII y a lo largo del s. XIV, tanto por cuestiones estratigráficas como por paralelos en otros recintos de la Sierra de Huelva, y de otro fábricas que igualmente a partir de paralelos fechamos con posterioridad a las anteriores, a lo largo del siglo XV, no descartando incluso que alguna pudiese llegar al siglo XVI.

Centrándonos en el primer grupo cronológico ( $2^{a} 1 / 2$ del s. XIII y a lo largo del s. XIV), cabria establecer dos tipos básicos, ambos fábricas de mampostería, cuya principal diferencia de una respecto a otra es el enfoscado (figuras 10 y 11). El primero de estos tipos está enfoscado a raspaterrón, 5-1 en la matrix Harris, con un mortero blanquecino, aún cuando en su mayor parte ha desaparecido. En este primer tipo los mampuestos presentan mayoritariamente tonalidades oscuras, y son de menor tamaño y menos regulares que en la fábrica de mampostería adscrita al periodo califal-taifa. Se disponen con tendencia a la horizontalidad, aunque sin 
ser tan nítida y marcada como en la mampostería califal-taifa. Cuando ha desaparecido el enfoscado, muestran anchas juntas, tomadas con mortero terroso, pobre en cal. La fecha de la fábrica enfoscada es relativamente fácil de establecer atendiendo a las características de la misma y sus relaciones estratigráficas. Por ejemplo, en el Lienzo B se comprueba que esta fábrica apoya en unos casos sobre fábricas de tapial y en otros, hacia el interior del patio de armas, sirven de forro al propio tapial. Además, interiormente podemos apreciar la edilicia de la fábrica, que básicamente consiste en dos muros careados al interior y exterior del lienzo y un relleno entre ambos de mampuestos irregulares, tierra y cal. Esta fábrica caracteriza típicamente a los castillos de la Sierra de Huelva de época bajomedieval, construidos entre finales del siglo XIII y siglo XIV. Una variante en cuanto al enfoscado, LC-5-3 en la matrix Harris, se presenta en el quiebro del Lienzo C. En este caso el enfoscado de recubrimiento, también blanquecino, es casi total y además aparece decorado con dibujos incisos con formas ovaladas antes de secado el mortero, que parecen pretender dibujar el contorno de los mampuestos. Bajo el enfoscado aparecen también ladrillos, formando lo que puede ser la reconstrucción de la esquina del quiebro.

Encontramos también esta fábrica en su tipo básico (5-1), en pequeñas reparaciones del los lienzos D y F, la Torre 9 al completo, lo que queda del Lienzo $\mathrm{H}$, la mampostería con la que se forra el tapial de la Torre 1, y la mayor parte de la Torre 2. Tras la fábrica de mampostería califal-taifa y el tapial, este tipo es la fábrica histórica con mayor representación en el recinto, y se puede considerar que con

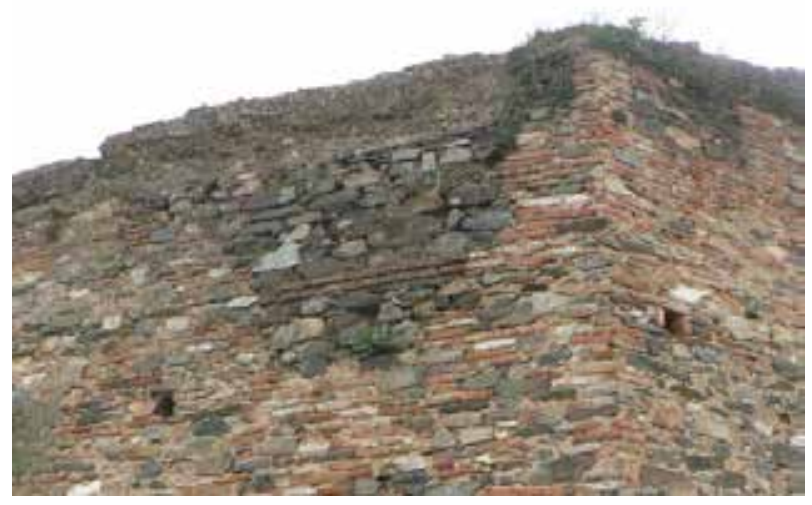

Figura 12: Detalle de fábrica de mampostería con alineamiento de ladrillos. Aparejo Toledano. LD/7-2. él se edifica la primera reforma que sufre el recinto tras la conquista cristiana.

El segundo de los tipos que adscribimos a este periodo es una fábrica también de mampostería, 5-2 en la matrix Harris. Es de aspecto descuidado en su formalización, sin disposición ordenada de los mampuestos y sin enfoscar, aunque técnicamente se ejecuta de forma similar a la fábrica anterior. Su representación es escasa, únicamente la hemos identificado en la parte baja de los lienzos B, F y G, Torre 8 , y una zona muy pequeña del Lienzo A en contacto con la Torre 2. En mayor medida aparece en la base de los lienzos, como elemento de nivelación, frecuentemente ataluzadas, a modo de zarpas. Si realmente se trata de un elemento constructivo de nivelación, es obvia que su cronología debe ser similar a la fábrica enfoscada. No obstante, en otros recintos fortificados de la Sierra de Huelva hemos encontrado fábricas similares a éstas reformando las fábricas originales y con cronologías que varían desde mediados del siglo XIV y a lo largo del siglo $\mathrm{XV}$. En este castillo también aparece a veces como recalce de los lienzos, y en la Torre 8 se ejecutó con esta fábrica la transformación de su planta, de cuadrada a circular. Si excluimos la transformación de la Torre 8 , podría ser por tanto que bajo este tipo estemos incluyendo obras ejecutadas en un periodo de tiempo dilatado, obras menores que en todo caso no creemos que cronológicamente puedan situarse más allá del s. XV.

El segundo grupo cronológico al que anteriormente hicimos referencia son las fábricas del siglo $\mathrm{XV}$ y posteriores, de las que básicamente vamos a diferenciar dos tipos. Por un lado fábricas de mampostería con verdugadas de ladrillos, a modo de aparejo toledano y por otro lado una fábrica también de mampostería que después describiremos.

La presencia de fábricas de mampostería enmarcadas por alineamientos de ladrillos en el Castillo de Almonaster la Real no ha sido señalada hasta ahora. Realmente, su significación espacial es escasa y mayoritariamente concentrada en varias zonas del Lienzo D. No existe tampoco homogeneidad, por cuanto prácticamente cada zona en la que la detectamos difiere formalmente de las anteriores. No obstante, atendiendo a la disposición de los ladrillos en las hiladas podemos concretar estas variaciones en tres subtipos.

El primero de estos subtipos, 7-2 de la matrix Harris, lo encontramos en la esquinera conservada de la Torre 5. Su análisis detallado pone de manifies- 


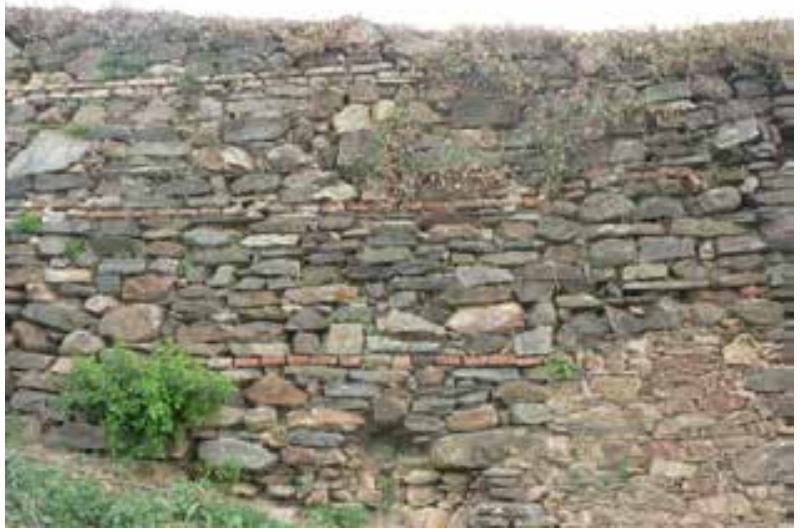

Figura 13: Fábrica de mampostería con alineamiento de ladrillos. Subtipo 7-4.

to dos fases constructivas. Una realizada en mampostería enmarcada por verdugadas de ladrillos, en la que alternan hilada de mampuestos separados por dos hiladas de ladrillos. Se conservan tres hiladas de mampuestos y dos de ladrillos. La otra fase de la esquinera está ejecutada íntegramente en ladrillos, conserva siete hiladas y sería coetánea al tapial. En la fábrica de mampostería y ladrillos interesa poner de manifiesto la disposición de los ladrillos. En la hilada inferior estos aparecen dispuestos transversalmente y longitudinalmente en la superior. Esta misma disposición de los ladrillos se repite en una pequeña reparación del Lienzo D (figura 12), a escasa distancia de la poterna, enmarcada entre las reparaciones de R. Manzano y la fábrica de tapial. En este punto se conserva una única doble hilada de ladrillos que separa dos zonas de mampostería, la inferior con tres hiladas de mampuestos y la superior con seis.

El siguiente subtipo, 7-4 de la matrix Harris, se localiza en el Lienzo D. Aproximadamente hacia su zona media encontramos un área con una fábrica de mampostería a hueso en la que aparecen tres tendeles horizontales de ladrillos colocados mayoritariamente en sentido transversal (figura 13). Dos de los tendeles están formados por una única hilada de ladrillos, y la superior por dos. Los tendeles de ladrillos separan paños de mampostería de aproximadamente 1,30 $\mathrm{m}$ de anchura, formados por entre 7 y 9 alineamientos horizontales de mampuestos.

En el último de los subtipos diferenciados existe si cabe mayor heterogeneidad. Ocupa tres áreas del Lienzo D, y su elemento común y diferenciador es que las líneas de ladrillo no siguen ningún patrón,

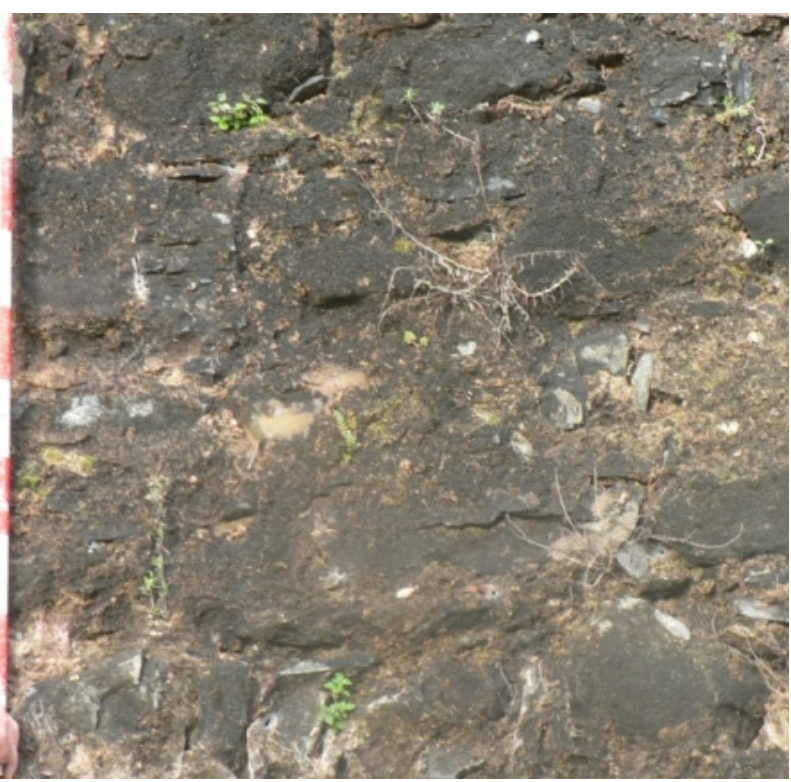

Figura 14: Detalle de la mampostía Tipo 3, con un enfoscado de recubrimiento total.

ni tan siquiera forman alineamientos completos, sino dispersos. Dos de las áreas muestran mechinales cuadrados de obras que no aparecen en la tercera. Estratigráficamente, en el Lienzo D podemos comprobar la posteridad al menos del subtipo 3 respecto a la fábrica de mampostería enfoscada que hemos fechado entre la $2^{\mathrm{a}} 1 \frac{1}{2}$ del XIII y el siglo XIV. Ello nos lleva a proponer para estas fábricas unas fechas de entorno al siglo XV. A favor de esta datación podemos argumentar varias razones, en primer lugar el tipo de fábrica, que podemos asemejar al aparejo toledano, que caracteriza a muchas de las iglesias y ermitas de la Sierra de Huelva, datadas aproximadamente en las mismas fechas. El aparejo toledano está presente en muchos de los lienzos del castillo de Aroche, en el que según los materiales cerámicos pudimos comprobar que se trataba de una refacción del siglo XV sobre el tapial.

La última de las fábricas históricas que vamos a diferenciar es también una fábrica de mampostería levantada con mampuestos de mediano tamaño tomados con mortero rico en cal, bastante regulares, con tendencia a formar alineamientos horizontales (figura 14). Presenta enripiado mayoritariamente pétreo entre los mampuestos, en ocasiones lajas o fragmentos de ladrillo de taco, de color rojo. Otra de sus principales características es el recubrimiento casi total de cal, aunque existen matices entre unas zonas y otras, tanto en el grado de recubrimiento 
del enfoscado, como en su tonalidad. Aparece en la segunda mitad del Lienzo A en dirección a la Torre 3 , y es la fábrica con la que se rehacen las Torres 3 y 6 , transformando sus plantas de cuadradas a circulares. En el Lienzo D también aparece en contacto con la Torre 6, y es el contacto con el Lienzo F, donde podemos apreciar la posterioridad constructiva de la misma respecto a la fábrica de mampostería enfoscada de la $2^{\mathrm{a}}$ 1/2 del XIII y hasta el siglo XIV. Para esta fábrica contamos además con la información deparada por el Sondeo 3 de la campaña de excavación del año 2007 (Rivera Jiménez y Romero Bomba, 2009), que nos permite definirla como un forro del lienzo preexistente, coetáneo con los últimos niveles de uso documentados en esta zona del recinto, en torno al s. XVI.

\section{FÁbricas CONTEMPORÁNEAS.}

Prácticamente todos los paramentos del castillo de Almonaster la Real han sido objeto en mayor o menor medida de actuaciones de restauración desde los años 50 hasta la actualidad, como claramente ponen de manifiesto los alzados que hemos elaborado (figura 2). El elemento común diferenciador de estas actuaciones es la utilización de morteros de cemento, existiendo una gran heterogeneidad tanto en lo relativo a los materiales como disposición de los mismos, que en nada ayuda a la comprensión y valoración del recinto. A nivel gráfico todas las variantes han sido agrupadas en un mismo tipo, que aparece signado con el numeral 2 precedido de las letras identificativas del paramento en la matrix Harris.

\section{CONCLUSIONES.}

A lo largo de las páginas precedentes hemos ido describiendo las distintas fábricas del castillo de Almonaster la Real. Básicamente podemos establecer tres tipos adscritos a época islámica, mampostería de los s. X-XI d.C., mampostería del s. XII d.C. y $1^{1^{a}}$ $1 / 2$ del s. XIII d.C. y fábrica de tapial también cronológicamente adscrita al periodo comprendido entre el s. XII d.C. y primera mitad del XIII d.C.

En la fase cristiana del recinto hemos diferenciado aquellas fábricas que consideramos de entre la segunda mitad del s. XIII d.C. y el siglo XIV d.C., identificando básicamente dos tipos, ambos de mampostería, una enfoscada a raspaterrón y otra sin enfoscar. El segundo grupo estaría formado por fábricas que consideramos del s. XV d.C. y posteriores, en el que hemos distinguido también dos tipos, fábrica de mampostería con verdugadas de ladrillos y fábrica de mampostería regular, con mortero rico en cal y enfoscado de recubrimiento. En algunos casos hemos podido establecer distintas variantes respectos a los tipos básicos.

Del análisis de la distribución de las distintas fábricas es posible extraer una importante conclusión, y es que el espacio ocupado por el recinto no ha sufrido variaciones sustanciales desde su fundación hasta la actualidad. Tradicionalmente se viene admitiendo un origen califal para el castillo de Almonaster la Real en el siglo X. De los diversos autores que se han pronunciado al respecto, Alfonso Jiménez ha sido el único que aporta datos en los que fundamentar su datación, derivándola de la datación de la propia mezquita, que a su vez fecha basándose tanto en la inscripción localizada en uno de los pilares de la Iglesia de la Concepción como en el estudio de paralelos con otras mezquitas, y especialmente sobre la base de planta del mihrab (Jiménez Martin, 1975, 107). De esta inscripción se ha ocupado con posterioridad C. Barceló Torres, quien la identifica con la shahāda, que la fecha en la segunda mitad del siglo XI a partir de sus paralelos procedentes de Cáceres y Lisboa (Barceló Torres, 2001, 51).Ahora contamos además con los materiales arqueológicos de las distintas campañas de intervención, y sobre todo los procedentes del sondeo 3 de la campaña del año 2007. Realmente, a partir de ellos no es posible una mayor precisión que la manifestada a lo largo del texto, s. X y XI d. $\mathrm{C}$, entre los periodos califal y taifa. Las cerámicas de la serie verde y manganeso recuperadas en los niveles inferiores del sondeos 3 son las que aportan mayor precisión cronológica. La muestra sin embargo no contiene formas, especialmente bases, que permitan discriminar si corresponden al s. X d.C o el s. XI d.C. El registro ergológico del castillo de Aracena, con una cultura material similar, remite como fecha más tardía a mediados del s. XI d.C (Romero, Rivera y Perez, 2012). Solo la ampliación de las zonas excavadas en el propio castillo de Almonaster la Real en un futuro próximo permitirá una mayor concreción.

Desde el punto de vista de su evolución, la reforma mediante el empleo de fábricas de tapial es la segunda fase constructiva del recinto, tras la que quedaría conformada su planta con la construcción de la Torre 1, adosándola a la Torre 2, para reforzar el sistema de la entrada principal. En esencia las reformas de este periodo parecen responder a 
un incremento de la altura de los paramentos preexistentes, y de ahí que mayoritariamente ocupe la mitad superior tanto en lienzos como en torres, excepto en el Lienzo F, que se rehízo en su totalidad. Los materiales recuperados en el Lienzo $F$ permiten datar su construcción hacia finales del siglo XII o principios del XIII d.C. (Rivera Jiménez y Romero Bomba, 2005). En el interior del Patio de Armas también se evidencia la amortización de los niveles de uso anteriores en la fase almohade, y la creación de nuevos niveles a una cota superior, claramente evidenciado en el Sondeo 2 de la campaña del 2007 con los sucesivos niveles de atarjeas (Rivera Jiménez y Romero Bomba, 2009).

Mayor variabilidad tipológica encontramos en las fábricas datadas desde la ocupación cristiana a mediados del siglo XIII d.C. hasta la construcción de la Plaza de Toros en el siglo XIX d.C. El problema radica en la inexistencia de constancia documental respecto a la realización de obras en todo este periodo. Únicamente las fuentes del siglo XVI nos acreditan la realización de las mismas entre 1546-1566, siendo arzobispo de Sevilla D. Fernando Valdés Salas, y su no realización entre 1569 y 1600. Sabemos también que existieron medidas fiscales que asegurasen los recursos necesarios para el mantenimiento del recinto a través de las Ordenanzas del Arzobispo Valdés, probablemente basadas en otras más antiguas (Jiménez Martín, 2006, 37). En el análisis paramental hemos diferenciado cuatro tipos distintos, con sus respectivos subtipos, prácticamente distribuidos por todo el recinto, lo que amplía la primera diferenciación realizada en los tipos C y D de A. Jiménez (Jiménez Martín, 1975, 107). Desde el punto de vista cronológico creemos más antiguas las fábricas que situamos entre la segunda mitad del s.XIII d.C. y a lo largo del s. XIV d.C. Se trata de fábricas de mampostería tomada con mortero de cal, formada por mampuestos de mediano tamaño, irregulares, unas enfoscadas con mortero de color blanquecino y otras sin enfoscar. Su principal característica es que responde al mismo sistema constructivo que hemos encontrado en otros castillos serranos, como los de Cala, Cumbres Mayores, Cumbres de San Bartolomé o Santa Olalla del Cala, cuya construcción se situaría entre la segunda mitad del siglo XIII d.C. y a lo largo del siglo XIV d.C. Son muros careados interior y exteriormente, con un relleno interior de mampuestos, cal y tierra, y tongadas de nivelación a base de cal, y cuando se ha conservado, enfoscado a raspaterrón de los mam- puestos (Romero Bomba y Rivera Jiménez, 2004a, 13; Rivera Jiménez y Romero Bomba, 2007, 9).En el castillo de Almonaster la Real encontramos este tipo forrando fábricas de tapial, tanto en el Lienzo B, como en el Lienzo D y la Torre 1, y recalzando los paramentos en el Lienzo B, D, F y G, y subsanando pérdidas en tapial o fábricas anteriores en distintas zonas. Con estas fábricas creemos también que se realizó la transformación de la Torre 8 a su forma circular, el forrado de la Torre 1, y la construcción de la actual Torre 9, en la que no hemos documentado en sus paramentos una fase anterior.

Un tipo de fábrica también presente en el castillo de Almonaster la Real es la mampostería con verdugadas de ladrillo. De este tipo hemos definido tres variantes, en todos los casos reparaciones menores. Su datación la fundamentamos por sus paralelos en el vecino castillo de Aroche, donde hemos podido documentar que son refacciones sobre el tapial, del s. XV y posteriores (Rivera Jiménez y Romero Bomba, 2005, 12). Fábricas también formalmente similares caracterizan muchas de las iglesias y ermitas mudéjares de la Sierra, mayoritariamente construidas a partir de la segunda mitad del s. XIV d.C. y siglo XV d.C. A tenor de las noticias históricas que nos llegan de finales del XVI sobre el estado del Lienzo D, en el castillo de Almonaster la Real

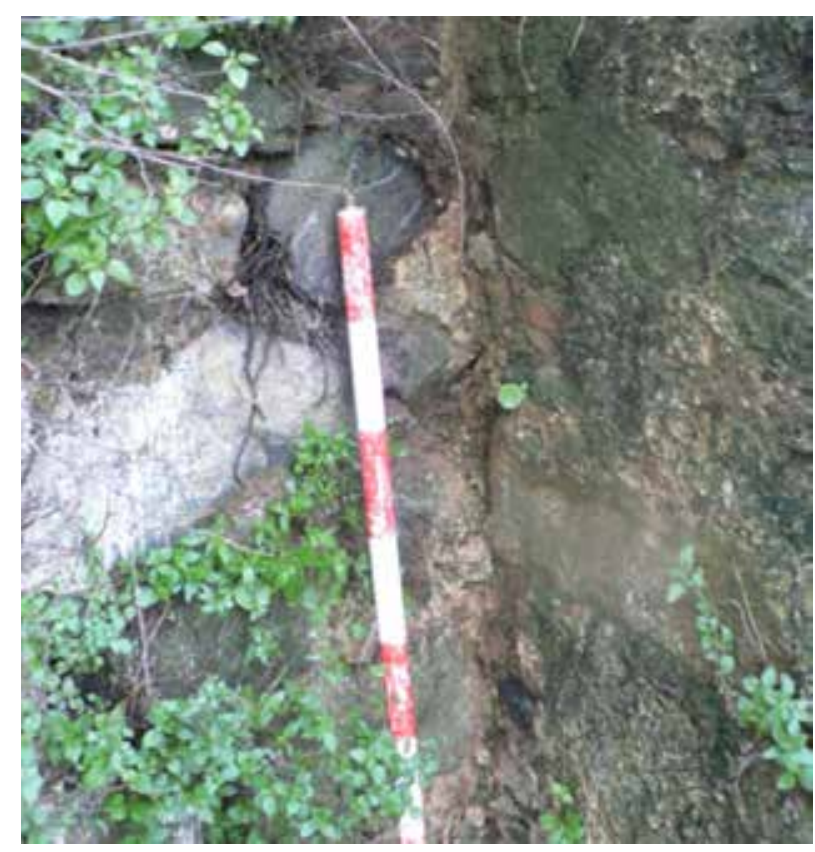

Figura 15: Relación estratigráfica entre la mampostería tipo 3 de la Torre 6, y la mampostería subtipo 5-1, del Lienzo E. 
pueden responder a esas fechas. No obstante, la heterogeneidad de este tipo obedece con seguridad a que se trata de distintas reparaciones realizadas en diversos momentos.

Finalmente, nos quedaría por concretar la información referente a la fábrica mampostería formada por mampuestos de tamaño medio, regulares, dispuestos horizontalmente, con algunos fragmentos de ladrillo y que presentaba un grado de recubrimiento casi total por enfoscado en la mayor parte de su superficie. En el Lienzo A, sirvió de forro a la unidad constructiva documentada en el sondeo 3, signada como S3/UC3 (Rivera Jiménez y Romero Bomba, 2009), y en la Torre 3 transforma la planta cuadrangular original en circular. En el Lienzo B se conserva un pequeño resto, inmediato a la Torre 3, que contacta con la fábrica de mampostería bajomedieval cristiana, enfoscada, adaptándose a una rotura de ésta. En la Torre 6 compone también el cuerpo cilíndrico de la torre, y en el Lienzo D se encuentra en el contacto entre la Torre 6 y el Lienzo E, lo que indica su posterioridad constructiva respecto a la fábrica de mampostería enfoscada (figura 15). En ambos casos por tanto es posterior a fábricas fechadas hasta el s.XIV d.C. Otro dato para su cronología lo podemos extraer de la estratigrafía de los distintos sondeos realizados en esta zona del patio de armas, y fundamentalmente del Sondeo 1 de la campaña del 2007, situado en el interior del Patio de Armas, perpendicularmente al Lienzo B, así como de la Unidad de Limpieza 1 (Rivera Jiménez y Romero Bomba, 2009). El primer dato a considerar es común a todos los sondeos estratigráficos realizados en el interior del Patio de Armas, y se define por su ausencia, es decir, no hemos documentado niveles ocupacionales del s. XVI d.C. y posteriores en ninguno de los sondeos realizados, cuando sabemos por la documentación histórica de la existencia de actividad en el recinto en estos momentos. Los únicos materiales aparecidos que nos ofrecen una cronología de estas fechas y posteriores aparecen en el nivel superficial, sobre todo de la Unidad de Limpieza L1 (Rivera Jiménez y Romero Bomba, 2009). Esta unidad se deposita a partir de la construcción de esta fábrica, siendo los niveles sedimentarios infrayacentes, anteriores a ella.

Directamente relacionado con la datación de la fábrica anterior, y muy significativo respecto a la evolución constructiva del castillo de Almonaster la Real, es la transformación de la planta de algunas de sus torres, de cuadradas a circulares. Con toda seguridad así ocurrió al menos en las Torres 3, 6 y 8. En la Torre 9 no advertimos evidencias de esa transformación, y pudo haberse rehecho comple-

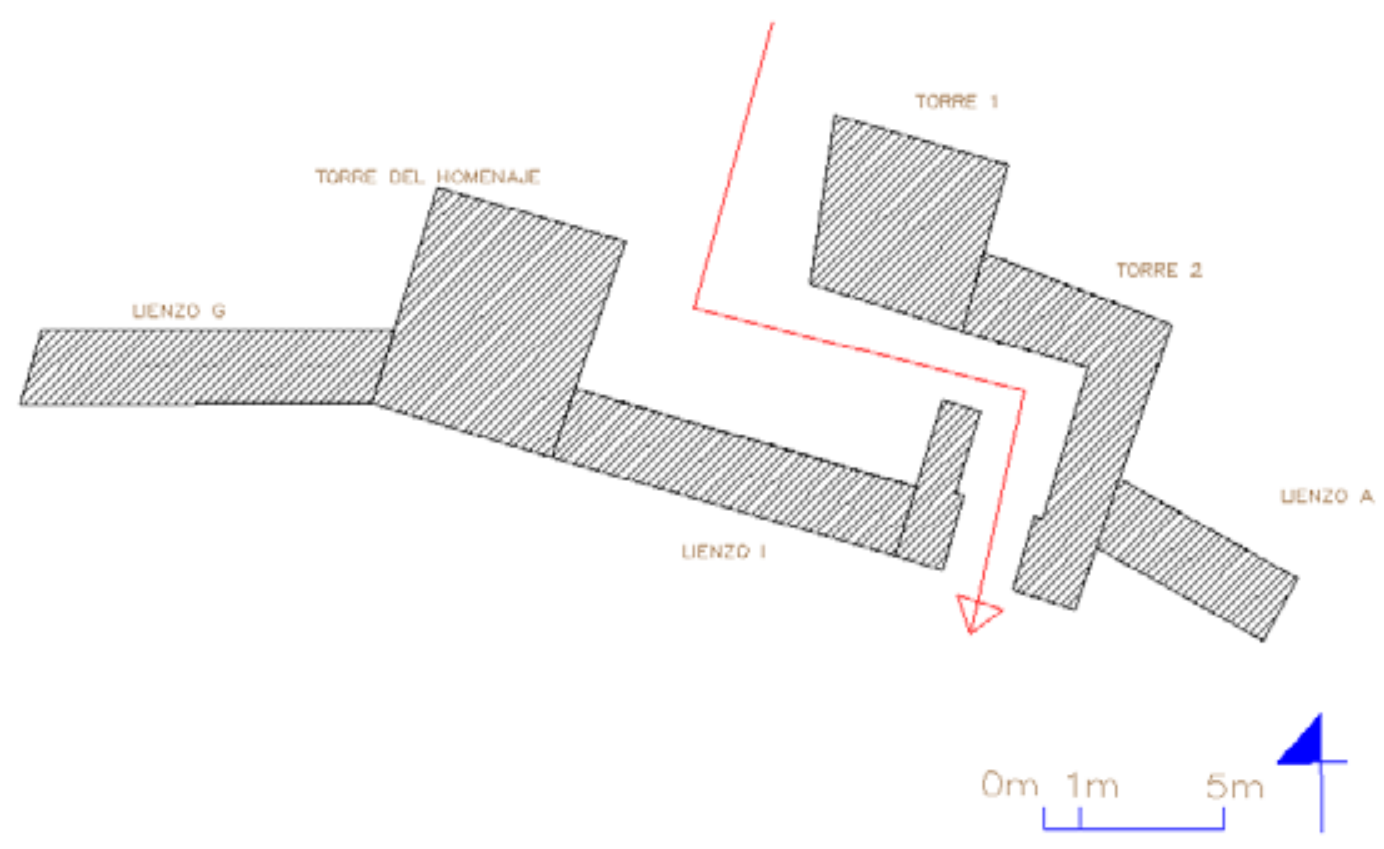

Figura 16: Croquis con el posible diseño original de la entrada principal en el castillo de Almonaster la Real (Huelva). 
tamente entre la segunda mitad del s.XIII d.C. y primera del s. XIV d.C. Pero también es evidente que por las diferencias y similitudes de las fábricas, dicha transformación no fue simultánea en todas las torres, sino que parece que en un momento determinado se transformaron las Torres 3 y 6 , mientras anteriormente lo había sido las Torre 8 y se había rehecho la Torre 9. La cuestión no obstante, no está exenta de una cierta problemática, por cuanto los planos conservados de hacia finales del s. XVI d.C. del Castillo de Almonaster la Real y elaborados por el Licenciado Espinosa dibujan todas las torres del recinto como cuadradas (Archivo General de Simancas, Guerra Antigua, Leg 157; Archivo General de Simancas, Diversos de Castilla, Leg. 27).

No podemos concluir este apartado sin hacer referencia, aunque sea brevemente, a la cuestión de las entradas al recinto. Respecto a la puerta secundaria hemos expuesto y argumentado la posible existencia de una torre flanqueándola por el Suroeste, que forzaría la entrada en eje acodado. Otra cuestión bien distinta es la entrada principal, que no será definitivamente resuelta hasta tanto no se acometan excavaciones arqueológicas en ese área. A partir de la información paramental y la información histórica proporcionada por el Licenciado Espinosa, una opción posible sería un esquema similar al de la figura 16. Este esquema necesariamente condiciona que desde la fase califal/taifa el acceso hubiese sido en eje acodado a través de la Torre 2 o Torre del Alcaide. En el periodo almohade la construcción de la Torre 1 redujo la distancia respecto a la Torre del Homenaje, forzando un nuevo quiebro, y por tanto reforzando el sistema defensivo. Y aún se reforzaría más si, como dibuja Espinosa, existió una barbacana, que cerraba el espacio existente entre la Torre del Homenaje y la Torre 1. La construcción de esta barbacana puede situarse en torno al siglo XV, como sucede en los castillos de Aroche y Cortegana.

\section{Bibliografía}

Barceló Torres, C. (2001), "Columnas arabizadas en basílicas y santuarios del occidente de al-Andalus", La islamización de la Extremadura romana, Cuadernos Emeritenses, 19, 87-138.

Jiménez Martín, A. (1975), La Mezquita de Almonaster, Huelva.

Jiménez Martín, A. (2006), "La Mezquita de Almonaster y su evolución historiográfica”, $E s$ piritualidad y convivencia en Al-Andalus, Huelva, 35-72.
Morales Martínez, A. J. (1976), Arquitectura medieval en la Sierra de Aracena, Sevilla.

Pavón Maldonado, B. (1996), Arquitectura islámica y mudejar en Huelva y su provincia, Huelva.

Paz, J. (1911), "Castillos y Fortalezas del Reino. Noticias de su estado y de sus alcaides durante los siglos XV y XVI ”, Revista de Archivos, Bibliotecas y Museos, XXV, 251-267.

Pérez Embid, F. (1944), "La Portada Manuelina de Almonaster la Real (Huelva)", Archivo Español de Arte, XVIII, 270-278.

Requena F. (1969), "Castillos señeros de la Sierra de Aracena: el de Almonaster. La Peña de Ali Jaled", Boletín de la Asociación Española de Amigos de los Castillos, 66, 263-279.

Rivera Jiménez, T. y Romero Bomba, E. (2005), "Proyecto de restauración del Castillo de Aroche. El enfoque interdisciplinar en la positivación de criterios arqueológicos”, Los castillos. Reflexiones ante el reto de su conservación, Sevilla, 217-229.

Rivera Jiménez, T. y Romero Bomba, E (2007), "Estudios arqueológicos del castillo de Cumbres de San Bartolomé, Cumbres de San Bartolomé (Huelva)", Vipasca, 2/2, 610-619.

Rivera Jiménez, T. y Romero Bomba, E (2009), "Estudios arqueológicos en el Castillo de Almonaster la Real (Huelva)”, IV Encuentro de Arqueología del suroeste peninsular, Huelva, 1374-1397.

Rivera Jiménez, T. y Romero Bomba, E. (e. p. ), "Estudios arqueológicos en el paño norte del Castillo de Almonaster la Real (Huelva)", Anuario Arqueológico de Andalucía/ 2005.

Romero Bomba, E. y Rivera Jiménez, T. (2004a), "Intervención Arqueológica en el Castillo de Cala (Huelva)", XII Jornadas del Patrimonio de la comarca de la Sierra, Huelva, 279-292.

Romero Bomba, E. y Rivera Jiménez, T. (2004b), "El criterio arqueológico en la restauración de los castillos de la Banda Gallega”, II Congreso Internacional sobre Fortificaciones: conservación y difusión de entornos fortificados, Sevilla, 137-141.

Romero Bomba, E. y Rivera Jiménez, T. (2009), "Secuencia de poblamiento en el castillo de Santa Olalla del Cala (Huelva)", IV Encuentro de Arqueología del Suroeste Peninsular, Huelva, 814-828.

Romero Bomba, E., Rivera Jiménez, T., Pérez Ma- 
cias, J.A (2012), “Cerámicas islámicas de Almonaster la Real y Aracena (Huelva)”, Arqueología Medieval, 12, 129-144.

Canto García, A; Romero Bomba, E; Rivera Jiménez, T., Romero de la Osa Fernández, O., (2015), "El hallazgo numismático de la Taifa de Sevilla en Aracena (Huelva), Onoba, 3, 163-170. 